\title{
Satellite Altimetry and GRACE Gravimetry for Studies of Annual Water Storage Variations in Bangladesh
}

\author{
Ole Andersen ${ }^{1, *}$, Philippa Berry ${ }^{2}$, Jennifer Freeman ${ }^{2}$, Frank G. Lemoine ${ }^{3}$, S. Lutsckhe ${ }^{3}$, \\ Flemming Jakobsen ${ }^{4}$, and Michael Butts ${ }^{4}$ \\ ${ }^{1}$ Danish National Space Center, DTU, DK-2100, Copenhagen, Denmark \\ ${ }^{2}$ EAPRS Laboratory, Gateway House, De Montfort University, The Gateway, Leicester, LE1 9BH, UK \\ ${ }^{3}$ NASA Goddard Space Flight Center, Code 926, Greenbelt, MD 20771, USA \\ ${ }^{4}$ DHI Water and Environment, Agern Alle, DK-2970, Hфrsholm, Denmark
}

Received 15 November 2006, accepted 23 June 2007

\begin{abstract}
Four different data sources have been compared with respect to observations of the annual water storage variations in the region of Bangladesh. Data from satellite altimeters and river gauges estimates the variation in surface water storage in the major rivers of Bangladesh.

The GRACE satellites measure the integrated mass change and hence the terrestrial soil moisture variations, which can also be estimated by a hydrological model (GLDAS). These types of observations enable the derivation of the integrated water storage in the entire region of Bangladesh.

For all data types, the annual signal has been estimated from a common dataset spanning the period 2003 and 2004. All four different data observe that water storage in Bangladesh is largely dominated by an annual signal with a phase peaking in early September. The annual variations in river level peaks roughly two weeks earlier than terrestrial soil moisture observations by GRACE observations and GLDAS model output.
\end{abstract}

Key words: Altimetry, Grace, River-level, Ground water

Citation: Andersen, O., P. Berry, J. Freeman, F. G. Lemoine, S. Lutsckhe, F. Jakobsen, and M. Butts, 2008: Satellite altimetry and GRACE gravimetry for studies of annual water storage variations in Bangladesh. Terr. Atmos. Ocean. Sci., 19, 47-52, doi: 10.3319/TAO.2008.19.1-2.47(SA)

\section{INTRODUCTION}

Bangladesh is a low lying country at the Bengali Bight, which is very prone to flooding and heavy seasonal variations in rainfall and water storage; the annual variation in terrestrial water storage is very large.

In this region, we will carry out a comparison between various data sources to investigate how closely they agree on determining the phase of the annual signal in terrestrial water storage. These data sources are GRACE observations, hydrological modeling, satellite altimetric observations of river levels and in-situ river gauge observations. We will compare the integral water storage observations from GRACE with the surface water storage observations in rivers from satellite altimetry and river gauges.

Bangladesh is a relatively small region $\left(144000 \mathrm{~km}^{2}\right)$

\footnotetext{
* Corresponding author

E-mail:oa@space.dtu.dk
}

and a low-lying country in the Meghna delta located at the confluence of three major rivers: the Ganges, the Brahmaputra, and the Meghna Rivers. The outline of the country and the major rivers are shown in Fig. 1. The Ganges and the Brahmaputra both have their origins in the Himalayas. After entering Bangladesh from the west and the north, these rivers, known locally as the Padma and Jamuna rivers respectively, merge to form the Meghna River. The Meghna River ultimately discharges into the Meghna Estuary (Jakobsen et al. 2002) in the northern part of the Bay of Bengal. 92 percent of the water in the Ganges, Brahmaputra, and Meghna Rivers are from catchments outside Bangladesh and mainly in the Himalayas.

The annual water storage variations in the rivers are dominated by the annual variation in climate and rainfall. Bangladesh is characterized by a tropical climate, i.e., cool, dry winter (November to February) with predominantly 


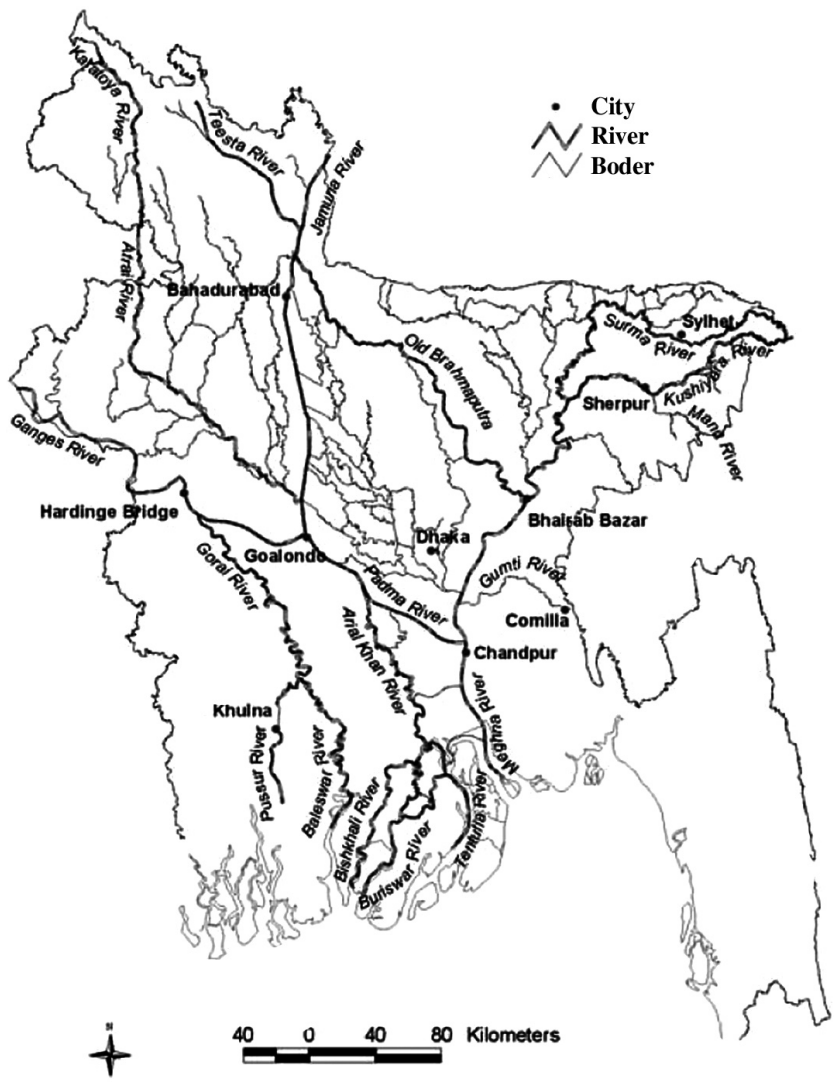

Fig. 1. Rivers, borders and the major cities in Bangladesh. From Jakobsen et al. (2005). The map is bounded by 22 and $25^{\circ} \mathrm{N}$ and 88 and $93^{\circ} \mathrm{E}$.

north-easterly monsoon winds; hot, humid summer (March to May); and wet monsoon (June to October) with annual rainfall varying from 3 to 5 meters of which 80 percent falls during the monsoon.

\section{GRACE GRAVIMETRY}

Changes in the gravity field is an integral indicator of mass re-distribution within the Earth system, and the GRACE twin-spacecrafts offer a new way of studying these temporal gravity field changes. GRACE can be used to study a number of processes: terrestrial water storage; changes due to surface and deep currents in the ocean; exchanges of water between land and ocean, like ice-melting and river runoff; variations of mass within the Earth; and changes in the atmosphere (Wahr et al. 1998).

The Gravity Recovery and Climate Experiment (GRACE) mission was launched in 2002 and is dedicated to providing an improved understanding of the Earth's mean and time varying gravity field. The twin GRACE satellites have now completed more than five successful years in orbit and are capable of measuring large-scale mass re-distributions within the entire Earth system with unprecedented accuracy (Tapley et al. 2004), but they are not capable of discriminating between the different contributors. However, by applying model corrections the hydrological signal, due to terrestrial water storage variations, can be isolated in the GRACE data (Wahr et al. 2004).

Global gravity field changes on annual scales from GRACE have been presented by Andersen et al. (2005b), and Wahr et al. (2004). Gravity field changes on inter-annual scales have been presented by Andersen and Hinderer (2004) and Andersen et al. (2005a). All of these studies were of a global or near global nature comparing GRACE observations with observations from global hydrological models.

The GRACE data used for this analysis are level 1B between January 2003 and July 2006. We apply a method for temporal gravity variation estimation using mass concentration blocks (mascon) developed by Rowland et al. (2005). Using this method we can derive sub-monthly mass flux at a high spatial and temporal resolution. Using $4^{\circ}$ by $4^{\circ}$ blocks at 10-day intervals, we estimate the mass changes over the region bounded by $20-40^{\circ} \mathrm{N}, 50-110^{\circ} \mathrm{E}$ centered on eastern India having 142 temporal 10-day solutions, which include Bangladesh.

In order to investigate the change in continental water storage, data were corrected for other known contributors to gravity changes. These include: contributions from solid Earth tides; ocean tides; ocean circulation (barotropic model); atmosphere; pole tides and N-body perturbations using various models.

Bangladesh covers an area of around $140000 \mathrm{~km}^{2}$. In principle Bangladesh will fit into one mascon. The mascon best representing Bangladesh was used for the present analysis. This mascon has it center at $23^{\circ} \mathrm{N}$ and $89^{\circ} \mathrm{E}$. Leakage from gravity signals from surrounding mascons is un-avoidable as gravity is an integrated measure of mass change.

The reason for using the mascon approach, and not the global spherical solutions from CSR, GFZ, and JPL (web2reference), is to obtain the maximum spatial and temporal resolution. First of all, the temporal resolution of the mascon solutions is 10 days compared with one month for the global solutions. Secondly, the mascon solutions do not suffer the same striping problems as the global GRACE solutions.

\section{HYDROLOGICAL MODEL}

Output from the Global Land Data Assimilation System (GLDAS) (Rodell et al. 2004; web1 reference); i.e., simulations with a hydrological model driven with observationbased forcing were used for this comparison. This model has previously shown very good comparison to GRACE observations of terrestrial water storage change on inter-annual scales (Andersen et al. 2005a) The GLDAS 3-hour and $0.25^{\circ}$ resolution soil-moisture fields were integrated over ten-day periods in order to mimic the temporal resolution of the GRACE data. 
For subsequent analysis temporal integration over the same periods as the available GRACE data was used. The GLDAS output data were subsequently averaged over the same spatial extent as the GRACE mascons for comparison purposes. For the present analysis, the $4^{\circ}$ by $4^{\circ}$ averaged cell centered at $23^{\circ} \mathrm{N}$ and $89^{\circ} \mathrm{E}$ for the same temporal period as GRACE was used. This averaged cell and mascon roughly represent the whole region of Bangladesh.

\section{RIVER GAUGE}

River gauge observations from the Chandpur River gauge in the center of Bangladesh were used for this investigation. The Chandpur River gauge is located at the confluence of the Bramaputna and Ganges into the Megna River (for location see Fig. 1). The Chandpur River data have been sampled using a very simple technique, in which the water level is measured manually every three hours (eight times per day) by the Flood Forecasting Warning Center (FFWC) in Bangladesh. Data from 2003 and 2004 were used. The data from 2004 were very non-typical as severe floods were experienced during July with more than 30 percent of the population of Bangladesh being evacuated.

\section{SATELLITE ALTIMETRY}

Satellite altimetry has been used for decades to obtain sea level height in the open ocean, but obtaining river level height is a novel use of such data. Obtaining river height from satellite altimetry is not a trivial task. In the open ocean, the return echoes used to define the height of the surface below the satellite, generally correspond well to a so-called Brown model (Challenor and Srokosz 1989). This enables precise range to surface information to be retrieved. On land and in rivers, it is generally necessary to reprocess or 'retrack' the individual waveforms to obtain accurate range to water or land targets below the satellite (Berry et al. 1997).

Using a rule-based expert system with ten retrackers configured for different terrain types, even complex echoes can be successfully retracked to yield heights over inland water as seen in Fig. 2. The footprint of the radar is typically several kilometers wide, but because water is far more reflective to microwave radiation at these frequencies than surrounding land, even very small targets a few tens of meters across can clearly be seen in the waveform shapes, which can be processed to yield height information (Berry et al. 1997, 2004). Four times as many lakes and river/lake systems are retrieved by the ERS/ENVISAT in ice mode compared with Topex/Jason due to the orbit-configuration; and ERS/ENVISAT generally enables far better monitoring of the annual and inter-annual variation of river and lake levels. The location of satellite data in Bangladesh and surrounding countries, where reasonable complete time series of river levels can be derived from satellite altimetry are shown in Fig. 3. A standard set of range and geophysical corrections were applied to the altimeter data (Fu and $\mathrm{Ca}$ zenave 2001).

\section{THE ANNUAL SIGNAL}

In a study of annual signals for terrestrial water storage, it is important to stress the fundamental fact that the resolution in both time and space of the various observations used for analysis are highly different. The various data sources do not even measure the same geophysical quantity, which adds complication to this. Therefore much caution should be taken upon correlating the various quantities.

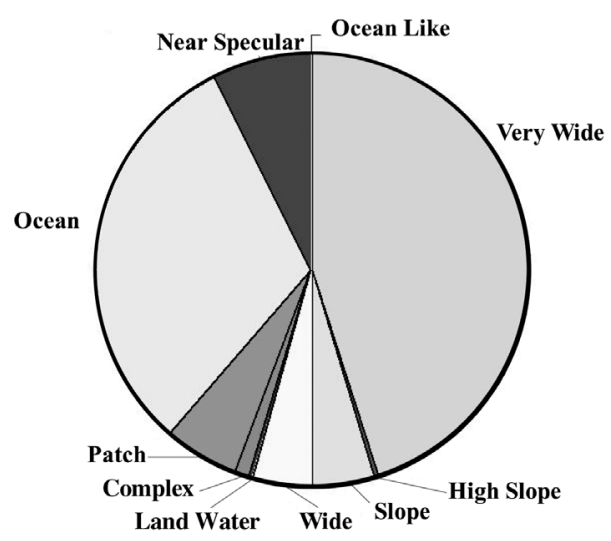

Fig. 2. Typical distribution between different waveforms over rivers and lakes. Less than 25 percent of the waveforms are so-called ocean waveforms and can hence be retracked using normal techniques. These are typically from very wide rivers and lakes. The retracking yields up to four times as many data over rivers and retracking is the only way of obtaining data in relatively small and narrow rivers.

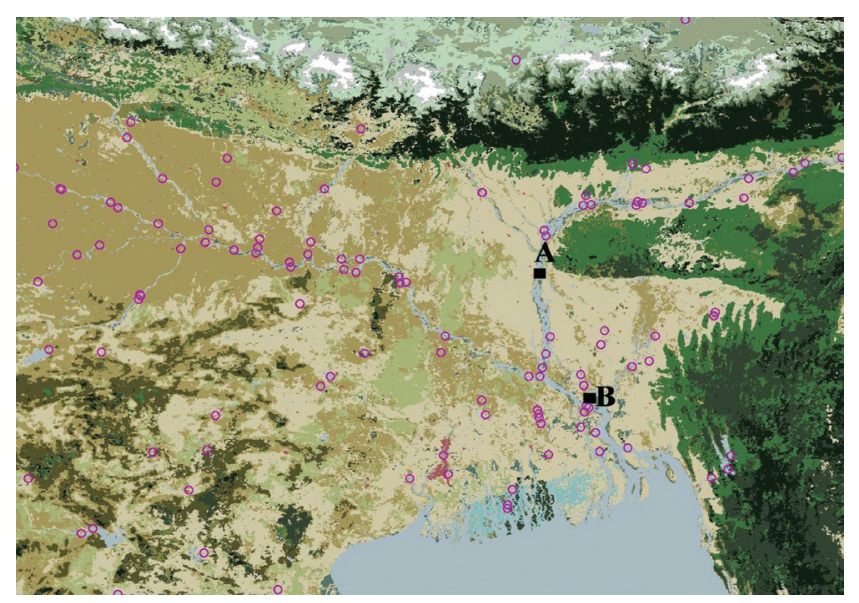

Fig. 3. Location (purple circles) of satellite altimetric observations in Bangladesh and surrounding countries. The circles correspond to ALL available river overpasses of mainly north-south going satellite ground-tracks from the ERS/ENVISAT and TOPEX/JASON satellites. Location A shows the location of data used in Fig. 4. The Chandpur River gauge is located at B, and altimetry from the closest purple circle have been used for the comparison in Fig. 5. 
The GRACE satellite observes regional water storage over the whole vertical water-column below the satellite (ground water + soil moisture + surface water) integrated over 10 days; and the hydrological model has been averaged to mimic these observations. The satellite and gauges observe the river level at specific points in time and at specific locations. Naturally, satellite altimetry and river gauge data differ. The time series from satellites are made from several crossing locations with footprints of kilometers sampling the river at intervals of weeks to a month, whereas the gauge is one in-situ point observation taken every 3 hours.

It is crucial to our investigation that the annual signal is believed to have both a regional and long term character and that the signal is captured adequately in all four sensors used for the investigation.

In Fig. 4, several altimetric time series from the Jamuna/Bramaputna River in the northern part of Bangladesh (location A in Fig. 3) are shown. Five different time series from 3 different satellite altimeters have been combined to complete this 12-year time series of the Jamuna River level. By combing several satellites one also improves the temporal resolution. This is because of the limitation due to the 35-day repeat sampling at each river pass by the ENVISAT/ ERS satellites. A dominant seasonal signal for the Jamuna River has been measured with amplitude of between 3 to 4 meters peaking in late August. The lowest water level is in late January. Variations in both amplitude and phase of the seasonal signal can be seen from year to year.

For all four datasets the annual changes were derived by modeling the signal as a mean plus an annual varying cosine and sine terms centered on 1 January 2004. As GRACE observes gravity field changes, corresponding water storage change was derived from temporal gravity field variations using a simple Bouguer plate correction, which connects changes in gravity to changes in an infinitely thin sheet of water (Knudsen and Andersen 2002). The Bouguer plate correction provides the "rule-of-thumb" that $1 \mu \mathrm{Gal}$ gravity

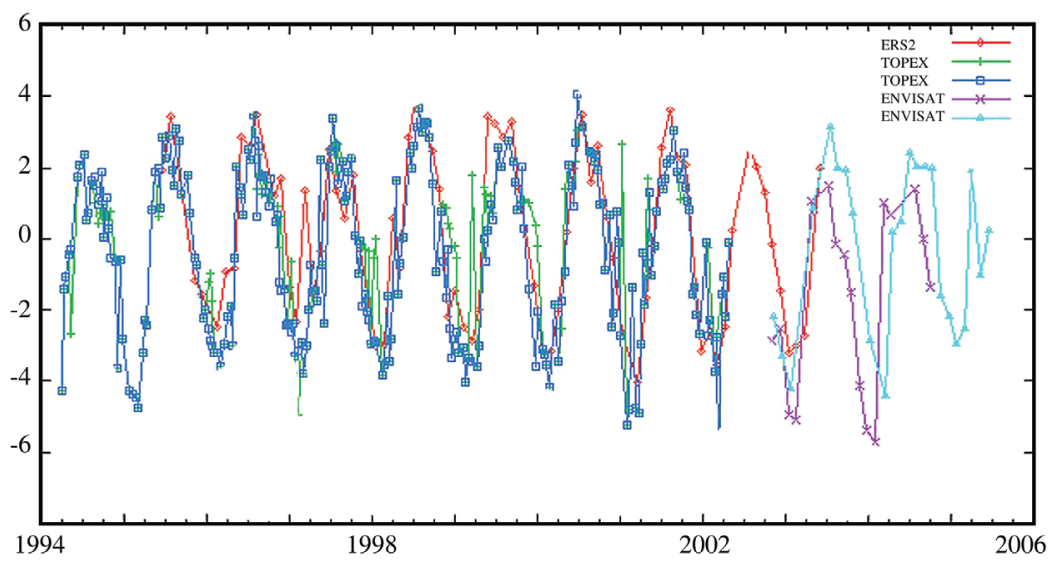

Fig. 4. River level observations (height in meters) in the Jamuna/Bramaputna river in the Northern part of Bangladesh shown with A in Fig. 3. River level data from three satellites have been used to derive this 12 years time series. change equates to $2.4 \mathrm{~cm}$ of water thickness change. The estimated annual signal from all four different data sources is shown in Table 1.

Table 1. Amplitude and phase of the estimated annual variation from four independent observations as close as possible to the Chandpur River gauge at location B in Fig. 3. The period 2003 - 2005 has been used for all data but the Chandpur gauge where only 210 days of data from 2003 was used (see Fig. 5 below).

\begin{tabular}{lcc}
\hline & Amplitude (m) & Phase \\
\hline Chandpur River gauge & 1.72 & 245 \\
ENVISAT Altimetry & 1.98 & 237 \\
GRACE soil moisture & 0.16 & 262 \\
GLDAS soil moisture & 0.17 & 261 \\
\hline
\end{tabular}

The gauge and the satellite generally agree well on both a phase of 244 days, corresponding to maximum river level around 1 September, and amplitude of 1.8 meters at this location. The phase of the altimeter peaks one week earlier than the gauge. However, the ENVISAT altimeter cannot resolve the phase with finer resolution than one month, due to the monthly sampling.

The phase of the annual variation in terrestrial water storage from GRACE peaks two weeks later than that observed by the river level. This corresponds to the middle of September (around day 260). The amplitude of both the GRACE derived terrestrial soil moisture and the GLDAS predicted soil moisture is in perfect agreement on both amplitudes of $16 \mathrm{~cm}$ and phase of 261 degrees.

Further comparison of the annual signal from the four data sources was obtained by computing temporal correlation and coherency as presented in Table 2. For this computation all datasets were re-sampled at 10-day intervals for as long a period as possible. This meant 81 10-day intervals for the GRACE and GLDAS datasets and 71 10-day intervals for the ENVISAT satellite. However, for the Chandpur tide gauge only 21 intervals during 2003 were available for comparison as can also be seen in Fig. 5. The temporal correlation is highest between the GRACE and GLDAS observations of integrated soil moisture variations where it reaches 0.97 . Similarly the correlation between river level heights between ENVISAT and the Chandpur tide gauge is 0.95 . The various other temporal correlations are generally close to 0.9 , which is also very high. The coherency gives an estimate of the variance scaling required to obtain similar variance. The coherency for both the two soil moisture datasets and the two river level datasets is 
Table 2. Temporal correlation (above diagonal) and coherency (below diagonal) at the Chandpur River gauge (Location B, Fig. 3). The various datasets have been averaged in 10-day intervals. The minimum number of joint observations has been used for the computation (i.e., 21 for all computations with the tide gauge). The coherency below the diagonal is the "variance scaling" of the quantity above the diagonal to obtain the variance of the quantity below the diagonal.

\begin{tabular}{lcccc}
\hline & Gauge (21 obs) & ENVISAT (71 obs) & GRACE (81 obs) & GLDAS (81 obs) \\
\hline Gauge & 1 & 0.95 & 0.88 & 0.89 \\
ENVISAT & 0.96 & 1 & 0.89 & 0.88 \\
GRACE & 0.09 & 0.10 & 1 & 0.97 \\
GLDAS & 0.09 & 0.09 & 0.97 & 1 \\
\hline
\end{tabular}

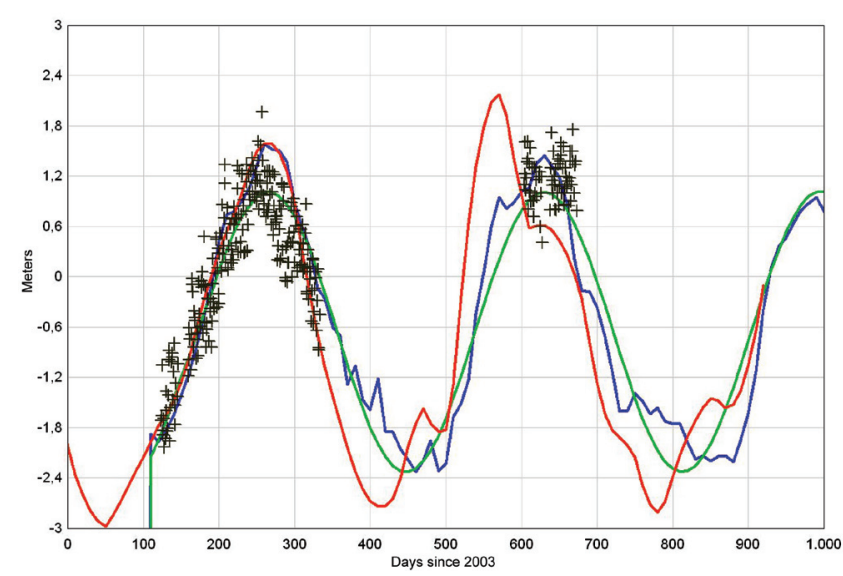

Fig. 5. Time series for the 2003 - 2005 period from the four different sources close to the Chandpur River gauge (black) in meters. Blue is GRACE derived terrestrial water storage (times 10). Green is GLDAS terrestrial water storage (times 10), Red is satellite altimetry from ENVISAT. The x-axis shows days since 1 January 2003.

practically one which means that they measure nearly the same amplitude of the quantity.

The time series for the period 2003 to 2005 for all the various data sources are shown in Fig. 5. The length of the Chandpur Gauge time series is only 210 days in 2003 and 90 days in 2004. For the computation in Tables 1 and 2 only the data from 2003 were used.

The phase of the annual signal is very nicely defined by the sub-daily sampling seen in Fig. 5. It can also be noted that the red curve representing the ENVISAT altimeter observations shows a relatively large difference between 2003 and 2004 in terms of the peak. This must be attributable to the relatively coarse temporal resolution of one month.

The Chandpur River gauge provides the most accurate observation of river levels at the particular location where measurements are made with accuracy of the order of five $\mathrm{cm}$. The accuracy of the satellite altimeter observations varies with the particular location, but at the Chandpur location the accuracy is around $10-20 \mathrm{~cm}$ with a small tendency to underestimate the lowest water level in the rivers (Berry et al. 2004).
Previous investigations of terrestrial water storage variations of GRACE have shown an accuracy of the $1-2 \mathrm{~cm}$ accuracy for spatial signals of $800 \mathrm{~km}$ wavelength and longer, with increased noise for increased spatial resolution (Wahr et al. 2004; Andersen and Hinderer 2005). In Bangladesh terrestrial water storage variations in surrounding mascons will affect the local solution. Even data from offshore in the Bay of Bengal might also affect the solution, though; the annual variation is expected to be small.

\section{CONCLUSION}

Annual water storage in Bangladesh has been estimated using four different kinds of observation. Satellite altimetry and river gauges estimate the variation in surface water storage. These observations have then been compared with GRACE satellite observations and observations from the GLDAS hydrological model which observers the total terrestrial water storage (surface and sub surface). In all cases the annual signal has been estimated from a common dataset spanning the period 2003 and 2004.

The four different sources of water storage variations observe an annual signal with nearly the same phase. The gauge and the satellite generally agree well with maximum river level at the Chandpur site in central Bangladesh at around 1 September, with amplitude of 1.8 meters at this location. The phase of the altimeter peaks one week earlier than the gauge. However, the ENVISAT altimeter cannot resolve the phase with finer resolution than one month, due to the monthly sampling.

The phase of the annual variation in terrestrial water storage from GRACE peaks two weeks later than that observed by the river level. This corresponds to the middle of September (around day 260). The amplitude of both the GRACE derived terrestrial soil moisture and the GLDAS predicted soil moisture is in perfect agreement on both amplitudes of $16 \mathrm{~cm}$ and phase of 261 degrees. The GRACE and GLDAS observations represent regional averages over nearly 400 by $400 \mathrm{~km}$ covering more or less the entire region of Bangladesh and as such its impressive that all four different data sources agree to such an extent. 
Future work will include a merging and use of altimetric observations of river level height into the hydrology model of Bangladesh. The model is also forced by precipitation and is run by DHI Water and Environment. This way the observations of river level variations from satellite altimetry and a few river gauges can be merged into a model which can be used to determine soil moisture variation in all of Bangladesh. Subsequently this model can be merged with a gravity model under development, which can then be used to determine the forward gravity field response to these river level variations. The ultimate goal is to try to make forward calculations of gravity response from the changes in water storage estimates by the model. This will enable direct comparison between the raw GRACE gravity observations and the gravity response of the hydrological model.

Acknowledgements We would like to acknowledge detailed comments and suggestions made by an anonymous reviewer, which improved the manuscript considerably.

\section{REFERENCES}

Andersen, O. B., and J. Hinderer, 2005: Global inter-annual gravity changes from GRACE: Early results. Geophys. Res. Lett., 32, L01402, doi: 10.1029/2004GL020948.

Andersen, O. B., S. I. Seneviratne, J. Hinderer, and P. Viterbo, 2005a: GRACE-derived terrestrial water storage depletion associated with the 2003 European heat wave. Geophys. Res. Lett., 32, L18405, doi: 10.1029/ 2005 GL023574.

Andersen, O. B., J. Hinderer, and F. G. Lemoine, 2005b: Seasonal Gravity Field Variations from GRACE and Hydrological Models, IAG symposium 128, Springer Verlag, 96-102.

Berry, P. A. M., H. Bracke, and A. Jasper, 1997: Retracking ERS-1 altimeter waveforms over land for topographic height determination: An expert systems approach. ESA Pub. SP414 Vol. 1, 403-408.

Berry, P. A. M., J. D. Garlick, and E. L. Mathers, 2004: Global scale monitoring of land surface water using multi-mission satellite radar altimetry. EGU $1^{\text {st }}$ General Assembly, Nice.

Challenor, P. G., and M. A. Srokosz, 1989: The extraction of geophysical parameters from radar altimeter return from a nonlinear ocean surface. In: Brooks, S. R. (Ed.), Mathematics in Remote Sensing, Institute of Mathematics and its Applications, 257-268.

Fu, L. L., and A. Cazenave, 2001: Satellite altimetry and Earth Sciences. A handbook of techniques and applications. In: Fu and Cazenave (Eds.), Int. Geophys. series 69, Academic Press, 465 pp.

Jakobsen, F., M. H. Azam, and M. U. Kabir, 2002: Residual flow in the Meghna Estuary on the coastline of Bangladesh. Estuar. Coast. Shelf Sci., 55, 587-97.

Jakobsen, F., A. K. M. Zeaul Hoque, G. N. Paudyal, and S. Bhuiyan, 2005: Evaluation of the short-term processes forcing the Monsoon River floods in Bangladesh. $\mathrm{Wa}$ ter Int., 30, 389-399.

Knudsen, P., and O. Andersen, 2002: Correcting GRACE gravity fields for ocean tide effects. Geophys. Res. Lett., 29, 19-1-19-4.

Rodell, M., P. R. Houser, U. Jambor, J. Gottschalck, K. Mitchell, C. J. Meng, K. Arsenault, B. Cosgrove, J. Radakovich, M. Bosilovich, J. K. Entin, J. P. Walker, D. Lohmann, and D. Toll, 2004: The global land data assimilation system. Bull. Amer. Meteorol. Soc., 85, 381-394.

Rowland, D. D., S. B. Luchcke, S. M. Klosko, F. G. R. Lemoine, D. S. Chinn, J. J. McCarthy, C. M. Cox, and O. B. Andersen, 2005: Resolving mass flux at high spatial and temporal resolution using GRACE intersatellite measurements. Geophys. Res. Lett., 32, L04310, doi: 10.1029/2004GL021908.

Tapley, B. D., S. Bettadpur, M. Watkins, and C. Reigber, 2004: The gravity recovery and climate experiment: Mission overview and early results. Geophys. Res. Lett., 31, L09607, doi: 10.1029/2004GL019920.

Wahr, J., M. Molenaar, and F. Bryan, 1998: Time variability of the Earth's gravity field: Hydrological and oceanic effects and their possible detections using GRACE. J. Geophys. Res., 103, 30205-30229.

Wahr, J., S. Swenson, V. Zlotnicki, and I. Velicogna, 2004: Time-variable gravity from GRACE: First results. Geophys. Res. Lett., 31, L11501 doi: 10.1029/ 2004GL019779.

Web1: http://ldas.gsfc.nasa.gov/.

Web2: http://podaac.jpl.nasa.gov/grace. 